\title{
DO ATO-FATO JURÍDICO (E DA VONTADE POSTA ENTRE PARÊNTESES)
}

DEL ATTO-FATTO GIURIDICO (E DELLA VOLONTÀ MESSA TRA PARENTESI)

\section{RESUMO}

O presente artigo tece considerações sobre a configuração do ato-fato jurídico dentro da teoria do fato jurídico, tal como elaborada por Pontes de Miranda, e sobre a sua compatibilidade com a relevância da vontade no direito privado. O escrito trata ainda do processo de isolamento da vontade entre os parênteses na tradução do mundo dos fatos ao mundo jurídico e da sua importância.

Palavras-chave: ato-fato jurídico; teoria do fato jurídico; Pontes de Miranda.

\section{RIASSUNTO}

Il presente articolo fa considerazionis ulla configurazione Del atto-fatto giuridico dentro La teoria del fatto giuridico, di Pontes de Miranda, e sulla compatibilità com La rilevanza della volontà nel diritto privato. Il testo si occupa del processo di isolamento della volontà traparentesi nella traduzione del mondo dei fatti al mondo giuridico e della sua importanza.

Parole chiave: atto-fattogiuridico; teoria Del fatto giuridico; Pontes de Miranda.

\section{INTRODUÇÃO}

Dentre as categorias utilizadas pela teoria do fato jurídico, tal como desenhada originalmente por Pontes de Miranda (1954), não é segredo que uma das mais polêmicas é a do

\footnotetext{
${ }^{1}$ Mestrando em Direito Privado e Graduado em Direito pela Faculdade de Direito do Recife, vinculada à Universidade Federal de Pernambuco. Integrante do Grupo de Pesquisa "Fundamentos do Direito Privado Contemporâneo" (UFPE/RDCC). Advogado.
} 
ato-fato jurídico, justamente por assinalar certa displicência com a vontade do sujeito, ${ }^{2}$ o que a muitos não parece afinado à marcha (quase militar) dos esforços em busca da valorização da vontade no âmbito do direito privado.

A questão, de fato, não é das mais singelas.

No intuito de explicar o que acontece com a vontade no ato-fato jurídico, Pontes de Miranda (1954a, p. 373) certifica que o quid psíquico é posto entre parênteses e, segundo a lição de Evanildo Bechara (2009, p. 612), a construção parentética significa, enquanto propõe, "um isolamento sintático e semântico mais completo dentro do enunciado".

Por isso, a operação tradutora que o ato-fato propõe entre o mundo dos fatos e do mundo do direito envolve um isolamento(estrutural e conjuntural) da vontade do agente, ${ }^{3}$ em ordem a tornar prevalecente o fato do sujeito sobre o ato de sua vontade, embora ambos não passem de refrações distintas do mesmo fenômeno.

O requinte da construção teórica, apesar de ostentar inegável coerência sistêmica, não deixa de configurar uma fuga à soberania da vontade no ambiente do direito privado, que vem em crescente histórica.

As linhas vindouras hão de lançar comentários sobre a escalada da vontade no âmbito do direito privado, sobre a configuração do ato-fato jurídico e, por fim, sobre a importância instrumental do isolamento da vontade na tradução dos elementos do mundo dos fatos ao mundo jurídico.

\section{DA ESCALADA HISTÓRICA DA VONTADE}

O primeiro estranhamento causado pelo construto do ato-fatoé o isolamento da vontade, porque o testemunho histórico, de fato, é pela soberania das volições.

\footnotetext{
${ }^{2}$ Essa insatisfação fica clara, por exemplo, na ponderação de Antonio do Passo Cabral (2016, p. 45), que entende "antiquadas" as premissas que embasam a categoria dos atos-fatos, uma vez que seria impossível, no atual estágio da ciência jurídica, desconsiderar a vontade do sujeito. Adianto, porém, que, no ambiente do direito processual, a questão já mereceu justa resposta por Eduardo Luiz Cavalcanti Campos (2016, p. 75-90).

${ }^{3}$ Pontes de Miranda (1954a, p. 373) parece tendente a essa leitura de isolamento da vontade, e não de sua exclusão: "Não se desce à consciência, ao arbítrio de se ter buscado causa a fato da vida e do mundo (definição de vontade consciente); satisfaz-se o direito com a determinação anterior".
} 


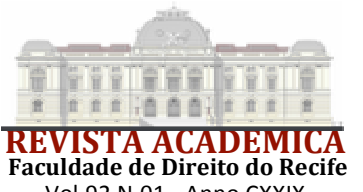

Faculdade de Direito do Recife

Vol.92 N.01 - Anno CXXIX

Mesmo no tratamento dos negócios jurídicos, a Antiguidade é rica em exemplos de pactos rituais, marcados por palavras e gestos sacramentais, nos quais o efeito jurídico vinculativo não surgia da vontade dos contraentes, mas do rito adotado. ${ }^{4-5}$

Por semelhante modo, não se desconhece que o direito romano conviveu durante alguns séculos com a figura dos contratos verbais, que se realizavam pela prolação de palavras solenes, como era o caso da stipulatio, que só se perfazia com a exata conjugação da forma sponsio (MOREIRA ALVES, 1971, p. 156-161)(IGLESIAS, 2010, p. 550-554).Nesse caminho, pois, até o tempo de Justiniano, o mero consenso - isto é, apenas a vontade - era impotente para criar obrigações civis. Ou seja, durante muito tempo, a vontade só tinha relevância jurídica quando manifestada em formas estreitas e específicas, que, aliás, eram mais relevantes nesse processo do que a própria vontade. ${ }^{6}$

A stipulatio, aliás, desempenhou um papel importantíssimo no sistema contratual romano antigo, pois o seu caráter obrigatório e, simultaneamente, abstrato tinha o condão de tornar exigíveis as obrigações contraídas originalmente sem as solenidades exigidas (IGLESIAS, 2010, p. 562)(CHAMOUN, 1968, p. 338-342)(CORRÊA, 1937, p. 149-157). Assim, a vontade, então impotente, ganhava força pela abstração da stipulatio. O fenômeno da novação, explica Soriano Neto (1937, p. 13-19), surge nesse contexto como um modo de tornar civis - e, assim, exigíveis - as chamadas "obrigações de boa fé". 7

Todavia, gradualmente, o caráter abstrato da stipulatio vai sendo demovido pelo direito pretoriano, o que se alia, num movimento histórico perceptível, ao crescimento dos contratos escritos. Daí, em 472 d.C., uma constituição imperial torna desnecessárias as palavras solenes para a estipulação, desde que a vontade dos contraentes fosse perceptivelmente concorde.

\footnotetext{
${ }^{4}$ John Gilissen (2016, p. 35) atribui essa carga ritualística verificada nas primeiras manifestações históricas do fenômeno jurídico ao que chama de "indiferenciação", já que, segundo anota, "nas sociedades arcaicas, o direito ainda está fortemente impregnado de religião".

${ }^{5} \mathrm{O}$ relato bíblico em torno da história de Rute, a moabita, por exemplo, dá conta de que, naquele tempo, por volta do século VI a.C., entre os hebreus, a permuta era comumente realizada perante dez anciãos e se perfazia pela troca das sandálias entre os contraentes (BÍBLIA de Estudo de Genebra, 1999, p. 309).

${ }^{6}$ Eugène Petit ([s.d.], p. 278, tradução livre)escreve que "a antiga regra, dominante ainda na época clássica e subsistente no tempo de Justiniano, é que o acordo das vontades, o simples pacto, não basta para criar uma obrigação civil. O direito civil não reconhece esse efeito senão às convenções acompanhadas de certas formalidades, cuja vantagem é a de dar mais força e certeza ao consentimento das partes e diminuir os pedidos ao cerrar em limites precisos a manifestação de vontade".

${ }^{7}$ Soriano Neto (1937, p. 13-19, gramática original) leciona que "a stipulatio é um contracto verbal, solemne, composto de simples pergunta e determinada resposta. [...] O seu valor jurídico obrigatório resulta, não exclusivamente do facto da promessa, mas do emprego da forma legal preestabelecida, sem nenhuma consideração a uma causa, isto é, fora das circumstancias em que ella se realiza" e, por isso, a novação romana "era, assim, a extincção de uma obrigação pela transfusão de sua materia numa estipulação. O conteúdo de uma obligatio, uma vez deduzido na stipulatio, que era uma forma geral de contractar, produzia uma nova obrigação e extinguia a antiga. Identico conteúdo, nova forma".
} 
Moreira Alves (1971, p. 162-163) anota que esse é um sinal da viragem da prevalência das verba (palavras sacramentais) para a soberania do consensus. ${ }^{8}$

A escalada da relevância da vontade é coroada no direito justinianeu, quando o mero acordo se torna bastante à criação de obrigações exigíveis, independentemente das formalidades sacramentais outrora exigidas (IGLESIAS, 2010, p. 501-504).

De se ter em conta, inclusive, que esse princípio da acionabilidade dos pactos informais e não solenes cresce e ganha novos motivos com a ascensão do direito canônico durante o Medievo. A simples promessa, por razões de fundo ético cristão, abandona a simplicidade de outrora e passa ser de necessária observância pelos contraentes (SCHIOPPA, 2014, p. 83).

No relato de Ascarelli (1947, p. 24-25), o princípio do consenso como gerador de obrigações exigíveis, amadurecido pelos canonistas, acaba por ser verificado concorde às necessidades encontradas no sistema nascente de comércio na baixa Idade Média, sendo certo que o formalismo do direito romano clássico era ineficiente para os usos do tráfico. Rompida, inclusive, a barreira da contratação entre ausentes, ${ }^{9}$ a teoria contratual entretecida às vésperas da Idade Moderna já está livre das ressalvas aos contratos escritos e bem mais próxima da liberdadedas formas e do domínio do consenso. ${ }^{10}$

Fato é que, na Idade Moderna, o contrato, como artefato da potência criativa da vontade, está longe de ser apenas um instrumento de trocas patrimoniais. A vontade (contratual) passa a ser o molde semântico de extensa parte dos fenômenos sociais. Os contratualismos de Hobbes, Locke e Rousseau são provas desse frenesi (ROPPO, 2009, p. 29-31).

Radbruch (1997, p. 281-289)inclui a ascensão da vontade contratual num movimento maior, de timbre jusnaturalista, que tem por desembocadura vestir as heteronomias, nomeadamente a força da lei, com indumentárias argumentativas tais que lhe façam parecer

\footnotetext{
${ }^{8}$ Em comentário que merece reprodução textual, Soriano Neto (1937, p. 13-19, gramática original) resume que "o direito material conquista o terreno ao velho formalismo, a stipulatio se despoja do seu caracter abstrato e, apeada de sua antiga realeza, se confunde na multidão plebléia dos contractos materialmente caracterizados". ${ }^{9}$ Segundo Moreira Alves (1971, p. 166), o último golpe na feição clássica da stipulatio foi dado por Justiniano, com a constituição imperial de 531 d.C., quando autorizou, na prática, que a estipulação fosse realizada entre ausentes, já que passou a ser suficiente que o contraente estivesse presente na cidade em alguma parte do dia em que a stipulatio ocorrera.

${ }^{10}$ No relato de Tullio Ascarelli (1947, p. 24-25), "a renascença do comércio e da vida econômica exigia um sistema contratual simultaneamente mais completo e mais elástico, assente, de um lado, na liberdade das formas e, de outro lado, no princípio geral da possibilidade das partes se obrigarem. [...] Os comercialistas, aliados nisto com os canonistas que, por seu turno, frisavam o valor do consentimento levados pelas suas premissas éticas, visam elaborar a disciplina geral dos contratos, estabelecendo o princípio geral do consentimento gerador da obrigação".
} 
autonomias. E é, talvez principalmente, por isso que a teoria do contrato social ganha relevo nesse contexto.

No âmbito do direito privado, a distinção sensível entre a vontade vinculante e a vontade vinculada não demora a ser vista, do que são sinais os debates surgidos entre a teoria da vontade e a teoria da declaração, que disputam os limites davinculação. ${ }^{11-12}$

Na reviravolta de 1789 e no seu caminho pouco linear até o Code Civil, dois dados acabam por tomar centralidade na alocação jurídica da vontade: a igualdade e a liberdade. A revolução extirpara as castas e os privilégios, portanto todos eram iguais, e retirara os gravames nobiliárquicos sobre os bens, pondo tudo à liberdade. Em 1804, o tratamento da vontade (contratual) revela-se, pois, instrumental à propriedade (ROPPO, 2009, p. 41-43),(CAENEGEM, 2000, p. 10-14).

É, porém, com a pandectística alemã que chega ao auge o "papel decisivo da vontade" no âmbito do direito privado (SOUSA, 1990, p. 15). ${ }^{13}$ De fato, enquanto os franceses trataram dos contratos entre os modos de aquisição da propriedade, os alemães lançam os contratos na classe maior, e mais complexa, dos negócios jurídicos (ROPPO, 2009, p. 49-50). ${ }^{14}$

Aparentemente bizantina, a questão de expor o contrato como uma espécie da categoria negócio jurídico (e não mais como uma "categoria de partida") culminou na supervalorização da vontade no conceito de contrato, justamente por ser um item central na conformação do negócio jurídico. Por isso, merece registro que o trunfo do Código Civil alemão é realizar, quase que por cascata, "a elevação da vontade a elemento chave da sua definição". Sendo isso decorrência do que Roppo (2009, p. 49-50) chega a chamar de "mística da vontade" no meio da produção

\footnotetext{
${ }^{11}$ Radbruch(1997, p. 281-289), em seu relato, destaca que a disputa travada entre tais teorias não esconde uma sempiterna discussão entre a leitura individual e a leitura social do direito privado, pois, enquanto para aquela importa apenas o quanto o sujeito quis se vincular, para esta toma relevo especial a expectativa gerada no outro.

${ }^{12}$ Sobre a disputa entre a teoria da vontade (ou as teorias da vontade, ou, ainda da vontade real) e a teoria da declaração (ou as teorias da declaração), de se conferir, com panorama geral sobre a questão: Miranda, 1989, p.21-58; e, Azevedo, 2017, p. 74-87.

${ }^{13}$ Registro a ponderação, em sentido levemente diverso, de Nelson Saldanha (2012, p. 485-489), para quem o Código dos Franceses já dava autonomia funcional e semântica ao conceito de ato jurídico.

${ }^{14}$ Naturalmente, não se quer dizer, com essas considerações sobre a contribuição do direito alemão, que o direito francês foi alheio ao tratamento dos vícios de vontade. Aliás, o gênio de Pothier sequer permitiria tal conclusão. Com efeito, Pothier (1906) chegou, em sua obra, a dedicar largas leituras aos vícios volitivos que poderiam alquebrar a higidez do contrato.
} 
jusnaturalista e iluminista, ${ }^{15}$ o BGB dedica longo espaço ao tratamento dos vícios volitivos, de modo a só garantir efeitos jurídicos na medida em que expressem a real vontade livre e espontaneamente manifesta.

Assim, com o apoio dos alemães, a vontade contratual ascende, nas palavras de Trabucchi (1974, p. 147), a "elemento dinâmico por excelência do mundo jurídico". Por isso, a importância da perquirição da validade dos negócios cresce na mesma proporção em que observa a crescente da relevância da vontade do sujeito (AZEVEDO, 2017, p. 41-42).

Propondo a síntese, no sentido hegeliano, Pontes de Miranda (1954b, p. 214220)enxerga nos rituais e nas cerimônias da Antiguidade (do que a sponsio foi talvez a melhor expressão) a tese, que seria a teoria da declaração, ainda que em momento germinal. Após isso, como antitese, surge a teoria da vontade (ou da vontade real), primando pelo respeito ao que efetivamente quis o sujeito no exercício de sua autonomia. Nesse encontro de águas, o sistema jurídico, sem descuidar das possibilidades de invalidação com base na não-coincidência entre o que se quis e o que se declarou, passou a ter a manifestação do sujeito como presumivelmente coincidente, isto é, "como pele da vontade".

Percorrido esse traçado histórico, é de se perceber, sem embargo dos contrapontos gerados pela necessidade de segurança no tráfico comercial, uma sensível crescente pela soberania e pela centralidade da vontade no regulamento do direito privado que termina por se tornar a chave-mestra da ordenação do sistema, sendo, então, coroada no influentíssimo Código Civil alemão de 1896 (RODRIGUES JR., 2015, p. 45-110).

\section{DA TRADUÇÃO AO MUNDO JURÍdICO E DA NECESSIDADE DE UMA CATEGORIA PRÓPRIA}

Essa escalada da vontade chegou ao direito brasileiro em ordem a, influenciando o pensamento de Clóvis Beviláqua (1975, p. 327), fazer constar no Código Civil de 1916 um livro dedicado a regular os fatos jurídicos, mas cujos três títulos regulamentavam, na verdade, os atos jurídicos (RÁO, 1981, p. 20) que o redator do Código definia como "toda manifestação de vontade individual, a que a lei attribue o effeito de movimentar as relações juridicas”.

\footnotetext{
${ }^{15}$ Sobre essa "mística da vontade", a que Enzo Roppo faz referência, Padoa Schioppa destaca que, além das teoriascontratualistas do surgimento do Estado já comentadas, a figura central de Hugo Grócio anotou que é da própria exigência racional, simultaneamente natural, ética e jurídica, que surge a diretiva "que impõe obedecer aos pactos (pacta sunt servanda)" (SCHIOPPA, 2014, p. 239).
} 
Além da preferência que subjaz a essa disposição de normas, e que denuncia uma macrovisão da organização do sistema de direito positivo, é de se pontuar que a definição de ato jurídico, a rigor, não deve ser limitada às manifestações de vontade. Pontes de Miranda(1954b, p. 395-398) alerta que também são atos jurídicos as manifestações de conhecimento (v.g., a notificação da cessão de crédito) e de sentimento (v.g., o perdão).

Acontece que, mesmo nesse cenário de poderio semântico da vontade, sempre houve o reconhecimento de que o fenômeno jurídico, por vezes, abstrai a vontade do sujeito e toma o ato como fato do homem (RUGGIERO, 1971, p. 214). Daí o ato-fato jurídico, sendo resultado dessa tradução seletiva dos elementos dos fatos ao mundo do direito.

Por ser assim, como sumaria Bernardes de Mello (2014, p. 195-196), sempre houve uma dificuldade teorética na alocação desses fatos jurídicos dentro do sistema, pois o caráter híbrido do ato-fato inspirou muitos autores a inserirem-no na classe dos atos jurídicos, em razão do caráter inegável da informação de que tais fatos são animados por atos humanos frutos de deliberação, e outros a incluírem-nos no plantel dos fatos jurídicos, dando prevalência, pois, à irrelevância jurídica da vontade na sua configuração. ${ }^{16}$

O próprio Clóvis Beviláqua (1972, p. 224), abordando a classificação com maior vagar, reconhece a existência de uma peculiar classe de atos jurídicos aos quais o ordenamento, uma vez incidente, dá consequências legais, "independentemente da intenção com que foram realizados".

Na mesma linha, Vicente Ráo (1981, p. 22-23) anota a existência do que chamou de ações materiais, põe-nasdentro da categoria dos atos jurídicos e dá-lhes distinção em razão do fato de que nelas a vontade é juridicamente considerada apenas como alicerce presumido de determinadas ações, pois que foram, por sua natureza, objeto de deliberação humana, mas não há relevância jurídica para composição elementar do fato jurídico.

Orlando Gomes (1992, p. 264-266), com inspiração alemã, insere o que chama de atos materiais (ou atos reais) no ajuntamento dos atos jurídicos e afasta-os da classe dos fatos jurídicos pela percepção inelutável de que, à sua base, está, necessariamente, uma atuação consciente humana. Nesse enleio, Gomes pondera que à configuração de tais atos reais o

\footnotetext{
${ }^{16} \mathrm{O}$ autor destaca que a escola francesa organizou orientação majoritária pela inclusão daquilo que classificamos como atos-fatos na classe dos fatos jurídicos, mas a escola têutica alinhou-se ao pensamento de que estão esses atos-fatos, mormente os atos reais, incluídos, na verdade, na classe dos atos jurídicos, o que inspirou ainda a sistematização italiana e brasileira da matéria (BERNARDES DE MELLO, 2014, p. 195-196). Com anotações sobre os arranjos alemães e italianos para a classificação dos fatos e dos atos jurídicos, de se conferir: Ráo, 1981, p. 33-44.
} 
fenômeno jurídico se contenta com o flagra do comportamento humano e do seu resultado natural, pressupondo, assim, consciência e vontade do agente.

Por semelhante modo, Alberto Trabucchi (1974, p. 132) também incluiu o que chamou de operações materiais (ou atos materiais) na classe dos atos jurídicos, sublinhando que são juridicamente relevantes em razão de serem causas de eventos exteriores e é ao acontecimento desses eventos que o sistema jurídico confere efeitos. ${ }^{17}$

Todavia, Pontes de Miranda (1954a, p. 372-394) deu solução distinta à questão e propôs que, nem atos, nem fatos, os atos-fatos constituem classe autônoma, apesar (e, talvez, justamente em razão) de comungarem elementos dos dois gêneros.

É do conjunto de características atinentes aos fatos jurídicos que os atos-fatos haurem a centralidade do resultado e colhem dos elementos dos atos jurídicos a relevância da conduta humana juridicamente significativa. Por isso, fala-se em "fato do homem" (PONTES DE MIRANDA, 1954a, p. 373).

No que pertine aos fatos jurídicos (stricto sensu), é preponderante o resultado (BERNARDES DE MELLO, 2014, p. 185). Assim, quanto ao fato jurídico "morte", tome-se o exemplo, é a verificação de sua efetiva ocorrência que interessa ao direito, ao que eventual conduta antecedente é irrelevante. É dizer: se o fato jurídico em sentido estrito“morte" adveio de um suicídio, dum homicídio ou de causas naturais, isso não é relevante para a sua configuração jurídica. Em suma, conduta humana relacionada, se houver, não integra o suporte fático (PONTES DE MIRANDA, 1954a, p. 187).

Quanto aos atos-fatos, também prepondera o resultado. Bernardes de Mello (2014, p. 189) pontua que, nessa seara, em verdade, juridicamente relevantes são os "fatos resultantes". Todavia, diferentemente do que ocorre aos fatos stricto sensu, sempre estará à base do ato-fato jurídico uma conduta humana, necessariamente humana, o que é indispensável à sua configuração (PONTES DE MIRANDA, 1954a, p. 373).

Já no que respeita aos atos jurídicos stricto sensu, prevalece, a seu turno, a conduta humana (ação ou omissão) da qual se pode concluir uma manifestação de vontade, de conhecimento ou de sentimento (PONTES DE MIRANDA, 1954a, p. 373).

\footnotetext{
${ }^{17}$ “Os atos ou operações materiais são caracterizados pelo fato de que a disciplina jurídica é ditada em relação a um determinado evento exterior. A consequência jurídica é justamente correlacionada ao acontecimento, assim como ocorre com os fatos naturais; aqui, no entanto, tem relevo a circunstância de que o evento é o resultado de uma atividade voluntária" (TRABUCCHI, 1974, p. 132, tradução nossa).
} 
Nesse contexto, mesmo o silêncio pode configurar ato jurídico, bastando que tal omissão importe, no caso, vontade. ${ }^{18}$ Por isso, de se ter claro que ao suporte fático dos atos está, necessariamente, a manifestação humana (que pode ser de vontade, conhecimento ou sentimento) (PONTES DE MIRANDA, 1954a, p. 451) (BERNARDES DE MELLO, 2014, p. 199).

Quanto aos atos-fatos jurídicos, porém, a conduta humana não dá ensanchas à sindicância em torno da vontade, do arbítrio, da consciência (PONTES DE MIRANDA, 1954a, p. 373) (LÔBO, 2013, p. 218). No movimento de tradução do ato humano ao mundo jurídico, ele ingressa como fato, "fato do homem", porque a norma jurídica incidente considera o determinismo e/ou a naturalidade de que o ato está impregnado. Então, o ato, embora humano, não devolve ao mundo jurídico qualquer vontade, conhecimento ou sentimento; passa a significar mesmo, e com propriedade, um fato. $\mathrm{O}$ actus ascende como factum. ${ }^{19}$

Por esse ajuntado de razões, os atos-fatos jurídicos, porque inconfundíveis, estão a merecer, como de fato já têm, uma categoria própria.

\section{DO PROBLEMA (E DA SOLUÇÃO) DO ISOLAMENTO DA VONTADE}

A vontade foi gradualmente elevada a chave-mestra do sistema de direito privado, alcançando um poder criativo de reconhecimento jurídico cuja extensão só se limita muito ao longe, e, no entanto, o fenômeno jurídico, em certas situações, opera de modo a exclui-la, por irrelevante, da tradução dos fatos. Esse é o quadro.

É hora, pois, de indagar o como e o porquê da construção parentética em torno da vontade naqueles fatos, tomados em sentido lato, nos quais esta é abstraída, resultando na configuração teórica do ato-fato jurídico.

\footnotetext{
${ }^{18}$ Pontes de Miranda (1954a, p. 396) assevera que "há de ser ato, positivo ou negativo, que revele vontade", inclusive que "o silêncio pode ser manifestação de vontade, de conhecimento ou de sentimento. É preciso que algo exista que permita tirar-se do calar o que se manifestou querer, conhecer ou sentir. Calar, só, não basta. É preciso ser concludente, isto é, que a pessoa cala tenha o dever de manifestar e se haja de ter o silêncio como uma das manifestações possíveis".

19 "Se o direito entende que é relevante essa relação entre o fato, a vontade e o homem, que em verdade é dupla (fato, vontade-homem), o ato humano é ato jurídico [...]. Se, mais rente ao determinismo da natureza, o ato é recebido pelo direito como fato do homem (relação 'fato, homem'), com o que se elide o último têrmo da primeira relação e o primeiro da segunda, pondo-se entre parêntese o quid psíquico, o ato, fato (dependente da vontade) do homem, entra no mundo jurídico como ato-fato jurídico. [...] Se esvaziamos os atos humanos de vontade (= se dela abstraímos = se a pomos entre parênteses), se não a levamos em conta para a juridicização, oactus é factum, e como tal é que entra no mundo jurídico" (PONTES DE MIRANDA, 1954a, p. 373).
} 
A ponderação que abriu este escrito, valendo-se dos contributos da linguística,encomenda-se para propor que a vontade, nos atos-fatos jurídicos, é isolada, encapsulada, tanto estrutural quanto conjunturalmente, porque essa é a função natural dos parênteses. É consabido que a partícula frasal parentética é plenamente destacável (sem prejuízo da compreensão total) do resto do enunciado - e é assim que o ato-fato se exibe no mundo jurídico, isolando a força semântica da vontade, sem perder qualquer conteúdo relevante. É que a hipótese legal, enquanto se dá a descrever, constrói, qualifica e seleciona a(s) realidade(s) (VILANOVA, 2010, p. 52-53).

Merece foros de cidade a lembrança de que o mundo jurídico não é mais do que "a soma, tecido ou aglomerado" dos elementos fáticos que ostentam relevância de monta a recomendar o seu transporte (PONTES DE MIRANDA, 1954a, p. 183), cujo bilhete de passagem é timbrado pela incidência da norma jurídica, que lhes conduz a outra dimensão (que é metafórica).Noutras palavras, o mundo jurídico, em seu processo tipificador, é menos um decalque do que uma colagem (VILANOVA, 2010, p. 173-174).

Os atos-fatos jurídicos são, em alguma medida, displicentes com a vontade do agente (e se autorizam à completa abstração dela), porque resultamda tradução ao mundo jurídico de atos humanos deliberados cujo resultado (puro e simples) é sobremaneira significativo a ponto de dispensar nova sindicância.O comportamento do sujeitotorna-se, pois, a testemunha única (e dá testemunho) de sua vontade (GOMES, 1992, p. 265).

Na condução interpretativa de Torquato Castro Jr. (2009, p. 130-139), a construção do ato-fato jurídico é um procedimento estratégico para deportar certas condutas humanas, pelos mais variados motivos, do escrutínio da validade dos atos - isso em prol da maior adequação do sistema às respostas mais "sensatas" quanto ao tratamento de determinados comportamentos.

Por isso, há uma bipartição das vontades e surgem, assim, a simples vontade (que não precisa passar pela sabatina do ordenamento) e a vontade negocial (que, por sua potência 
criativa, não passa sem prova). Nesse contexto, a vontade que anima os atos e os negócios jurídicos precisa ser bem valorada, mas a simples vontade (a desses atos que mais parecem fatos) só precisa existir. ${ }^{20}$

Quanto a isso, Pontes de Miranda (1954b, p. 3-4) é enfático ao ponderar que os atosfatos jurídicos não se submetem ao plano da validade ou, noutras palavras, não são postos à verificação de sua aptidão para atuar e permanecer no mundo jurídico.

No esquema de Pontes de Miranda (1954a, p. 372-394), que é seguido por Bernardes de Mello (2014, p. 188-197), são três as categorias de atos-fatos jurídicos: os atos reais (ou materiais); os atos que causam danos sem culpa; e, os atos que ensejam caducidade sem culpa.

Acerca dos atos reais, também chamados de atos materiais, primeira categoria dessa sistematização, de se dizer que são assim nominados "por serem mais dos fatos, das coisas, que dos homens". Por ostentarem essa peculiaridade, por exemplo, são atos-fatos jurídicos a ocupação, a descoberta de tesouro, bem como a tomada, a transferência por tradição e o abandono da posse (PONTES DE MIRANDA, 1954a, p. 373-374).

Em todos esses casos, o comportamento do sujeito ostenta um significado próprio no mundo jurídico e, por isso mesmo, dispensa incursão sobre sua vontade e, em conseguinte, sobre sua capacidade. Nesse ambiente, quem se assenhora de um bem móvel tomou posse; quem entregou-o corporalmente a outrem transferiu essa posse e quem deixa de exercer poder fático sobre o bem abandonou a posse. As condutas, por si sós, têm, pois, conteúdo suficiente para a dimanação eficacial no plano jurídico (BERNARDES DE MELLO, 2014, p. 189).

É impossível deixar de perceber que o que informa a caracterização dos atos reais (e a sua parentetização da vontade) é a sombra de indiscutibilidade de sua ocorrência, o que constrange, em alguma medida, o escrutínio do mundo jurídico sobre a capacidade do agente.Assim, por exemplo, na descoberta de tesouro, não é razoável (e não parece produzir bons frutos) debater a capacidade de quem o descobriu, principalmente porque, ausente acapacidade do descobridor, o direito teria que continuar a considerar res nullius a coisa e, assim, o saqueador do incapaz se tornaria, segundo as normas incidentes, legítimo possuidor do tesouro (PONTES

\footnotetext{
20 “'O chamado 'ato-fato jurídico', já na própria designação que lhe foi reservada por Pontes, assume feição paradoxal. É ato e fato ao mesmo tempo? Não é difícil perceber que se trata 'materialmente' de um ato, porque o suporte fático não pode compreender sem a efetiva presença da vontade humana. Mas há que se ter presente que, do ponto de vista normativo, seu funcionamento é em todo idêntico ao do 'fato jurídico em sentido estrito'. [...] O direito, pode-se dizer, apenas precisa supor que haja alguma vontade presente no suporte fático, para que se entenda configurada a fattispecie e admitida a incidência da norma. Nesse sentido, não haverá o direito que valorar essa vontade, apenas que reconhecê-la" (CASTRO JR.,2009, p. 130-139).
} 
DE MIRANDA, 1954a, p. 379). E é por isso que se afasta a sindicância sobre a vontade e a capacidade na leitura desses casos (CASTRO JR., 2009, p. 131).

No que respeita aos atos que causam danos sem culpa, ainda chamados de atos-fatos indenizativos, Pontes de Miranda destaca que há alguns princípios ${ }^{21}$ que, excepcionando o princípio geral da culpa, informam a sua caracterização como atos-fatos jurídicos: a proteção do interesse mais relevante, a responsabilização pelo perigo atrelado ao interesse e pelo exercício da tutela jurídica e a responsabilidade pela palavra (1954a, p. 386-387).

Não sendo o objetivo deste escrito descer às minúcias da caracterização de cada ato-fato jurídico previsto no ordenamento, é de se destacar que, nessa classe, os atos humanos são vertidos em atos-fatos a fim de encapsular a culpa, de, isolando-a, tornar prevalecente o nexo entre a conduta do agente e o dano verificado, independentemente da ilicitude do comportamento do sujeito (BERNARDES DE MELLO, 2014, p. 189-192).

Nesse traçado, o plano jurídico, em sua tradução do plano fático, dedica-se a definir a responsabilidade civil como o meio de restabelecimento do equilíbrio (jurídico ou econômico) causado pelo dano, como pontuava Aguiar Dias (1954, p. 43).

É conhecido o caso de responsabilidade por proteção do interesse de relevo, como é o caso da indenização por desapropriação (PONTES DE MIRANDA, 1954a, p. 389). São famosos, ainda, os exemplos de responsabilidade pelo perigo atrelado ao interesse, consagrados pela teoria do risco da atividade, tal como adotada no Código de Defesa do Consumidor (MIRAGEM, 2013, p. 495-501), e, igualmente, são conhecidos os casos de responsabilidade pelo exercício da tutela jurídica, como prevê o Código de Processo Civil para os danos advindos da efetivação da tutela provisória posteriormente revogada (ASSIS, 2016, p. 482).

Curioso caso traz a categoria da responsabilidade pela palavra, em virtude da sua sutil presença no direito contratual e no direito societário. À guisa de ilustração, cabe trazer o exemplo das chamadas "cartas de conforto" (comfort letters), que, divididas entre "fracas" e "fortes", constituem declarações ofertadas por uma companhia controladora para dar segurança a uma operação bancária entre uma casa financeira e uma de suas companhias controladas. Seguindo a linha de Paes de Barros Leães (2001, p. 207-216), mesmo quando essas cartas são "fracas",

\footnotetext{
${ }^{21}$ Ao que tudo indica, os "princípios" têm aí o sentido apontado por Pontes de Miranda (1973, p. 66) em outras obras como esses artefatos abstratos que, pretendendo sintetizar a realidade do direito, se dão a "platonizar" o sistema, organizando as normas jurídicas dispersas de modo ordenado.
} 
contendo apenas declarações informativas sobre o funcionamento do grupo econômico, há responsabilidade pela palavra em caso de dano. ${ }^{22}$

Por derradeiro, há os atos que ensejam caducidade sem culpa, sobre os quais se pode dizer que o plano jurídico sói de abstrair as razões da inatividade do sujeito titular do direito (da pretensão ou da ação), reconhecendo a preclusão operada. Assim, são atos-fatos os que dão ensanchas à prescrição e à decadência (PONTES DE MIRANDA, 1954a, p. 392).

Com efeito, à ocorrência da prescrição ou da decadência o mundo jurídico se contenta com a inação do titular do direito pelo prazo legalmente demarcado, sem perquirir os motivos da sua omissão (BERNARDES DE MELLO, 2014, p. 192-195), o que traz à tona a percepção de que tais institutos perfazem proteções legais ao devedor, em nome da paz social, e não punições ao credor (ALBUQUERQUE JR., 2013, p. 485-498).

Lembra Pontes de Miranda (1955, p. 392) que é ultrapassada a leitura de que a prescrição constitui punição ao credor inativo, o que então inspiraria a investigação em torno das razões da sua negligência, ideia que ronda o sistema normativo brasileiro desde, pelo menos, as Ordenações Filipinas. Porém, a prescrição, uma vez ocorrente, gera direito excepcional ao devedor e àquele que não é devedor (e pode, em razão do decurso do tempo, não ter mais prova da inexistência da dívida). Serve, pois, o instituto à paz social e à segurança jurídica, destinandose a encobrir a eficácia das pretensões que o alegado devedor, por diversidade de motivos mas com confiança, já tinha por "ilevantáveis".

É por isso que, sendo irrelevantes as razões da inatividade do credor para a composição do seu suporte fático, das quais o sistema jurídico abstrai após um cotejo de valores contrapostos,a prescrição configura um ato-fato jurídico.

Com esses apontamentos, de se concluir que os atos-fatos jurídicos, no trajeto de isolarem semanticamente a vontade do sujeito, dela abstraindo, fazem-no em atenção a princípios outros, igualmente dispostos no ordenamento jurídico, sem que isso importe vilipêndio à força criativa da volição nos espaços em que legitimamente atua.

\section{CONCLUSÃO}

\footnotetext{
22 "Mesmo quando a carta de conforto vem vazada somente com declarações informativas, atinentes às relações intercorrentes entre a sociedade emitente e a que aspira ao financiamento, sempre está presente a intenção jurídica de suscitar a confiança do destinatário quanto à solvência da controlada e ao subsequente adimplemento do financiamento. E essa confiança, incutida em outrem, gera obviamente uma responsabilidade para o emitente, ou seja, cria um vínculo de natureza jurídica entre as partes interrelacionadas" (LEÃES,2001, p. 207-216).
} 
"Acontece considerarmos que este efeito provém daquela causa, quando afinal ela foi outra, muito fora do alcance do entendimento que temos e da ciência que julgávamos ter". É José Saramago (2017, p. 12) quem esmiúça nessas palavras o temor intermitente na missão humana de conectar causas e efeitos, construindo criativamente esses nexos e tentando emprestar um sentido à ordem dos acontecimentos do mundo.

Colocar a vontade entre parênteses, isolando-a do resto do enunciado e autorizando a sua abstração, é o modo pelo qual o ordenamento jurídico dá sentido a certos fatos, tornando-os causas e dando-lhes efeitos.

De fato, o fenômeno jurídico, nesses casos, põe a vontade do agente além dos seus domínios, além de sua ciência, o que serve aos fins do próprio sistema normativo. A ignorância da vontade autoriza o mundo jurídico a evitar sindicâncias desnecessárias (ou perigosas) sobre a capacidade do agente, quando é clangoroso o fato ocorrido.

Se o incapaz produziu uma escultura, não interessa a sua capacidade. Foi fruto de sua arte e engenho, e é aquisição originária dele. Por isso, a criação artística (científica e intelectual) é ato-fato jurídico. O sistema permite-se afastar as barreiras de seu próprio circuito para se satisfazer com a "simples vontade", para a qual basta existir.

A vontade é posta fora dos muros do mundo jurídico na tradução desses eventos, porque, para o sistema, não é a volição humana a causa dos efeitos que a norma, incidindo, faz irradiar. A causa, a toda evidência, é o clangor do fato, do "fato do homem".

\section{REFERÊNCIAS}

ALBUQUERQUE JR., Roberto Paulino de. A prescritibilidade das ações (materiais) declaratórias: notas à margem da obra de Agnelo Amorim Filho. In: ALBUQUERQUE JR., Roberto Paulino de et al. (Coord.). Prescrição e decadência: estudos em homenagem a Agnelo Amorim Filho. Salvador: Juspodivm, 2013. p. 485-498.

ASCARELLI, Tullio. Panorama do direito comercial. São Paulo: Livraria Acadêmica Saraiva \& Cia, 1947.

ASSIS, Araken de. Processo civil brasileiro. São Paulo: Revista dos Tribunais, 2016.v. 2. t. 2.

AZEVEDO, Antonio Junqueira de. Negócio jurídico: existência, validade e eficácia. São Paulo: Saraiva, 2017. 
BECHARA, Evanildo. Moderna gramática portuguesa. Rio de Janeiro: Nova Fronteira, 2009.

BEVILÁQUA, Clóvis. Código Civil dos Estados Unidos do Brasil comentado por Clóvis Beviláqua. Edição Histórica. Rio de Janeiro: Editora Rio, 1975.

BEVILÁQUA, Clóvis. Teoria geral do direito civil. Brasília: Ministério da Justiça, 1972.

BÍBLIA de Estudo de Genebra. São Paulo: Sociedade Bíblica do Brasil, 1999.

CABRAL, Antonio do Passo. Convenções processuais. Salvador: Juspodivm, 2016.

CAENEGEM, R. C. Van. Uma introdução histórica ao direito privado. São Paulo: Martins Fontes, 2000.

CAMPOS, Eduardo L. C.. Ato-fato processual: reconhecimento e consequências. Revista de processo, São Paulo, ano 41, v. 254, p. 75-90, abr. 2016.

CASTRO JR., Torquato. A pragmática das nulidades e a teoria do ato jurídico inexistente: reflexões sobre metáforas e paradoxos da dogmática privatista. São Paulo: Noeses, 2009.

CHAMOUN, Ebert. Instituições de direito romano. Rio de Janeiro: Forense, 1968.

CORRÊA, Alexandre. Prelecções de direito romano. São Paulo: Linotechnica, 1937.

DIAS, José de Aguiar. Da responsabilidade civil. Rio de Janeiro: Forense, 1954.t. 1.

GILISSEN, John. Introdução histórica ao direito. Lisboa: Fundação Calouste Gulbenkian, 2016.

GOMES, Orlando. Introdução ao direito civil. Rio de Janeiro: Forense, 1992.

IGLESIAS, Juan. Direito romano. São Paulo: Revista dos Tribunais, 2010.

LEÃES, Luis Gastão Paes de Barros. Carta de conforto como obrigação de garantia vinculante. Revista de direito bancário e do mercado de capitais, São Paulo, v. 13, p. 207-216, 2001.

LÔBO, Paulo. Direito civil: parte geral. São Paulo: Saraiva, 2013.

MELLO, Marcos Bernardes de. Teoria do fato jurídico: plano da existência. São Paulo: Saraiva, 2014.

MIRAGEM, Bruno. Curso de direito do consumidor. São Paulo: Revista dos Tribunais, 2013.

MIRANDA, Custódio da Piedade Ubaldino. Interpretação e integração dos negócios jurídicos. São Paulo: Revista dos Tribunais, 1989. 
MOREIRA ALVES, José Carlos. Direito romano. Rio de Janeiro: Forense, 1971.v. 2.

PETIT, Eugène. Tratado elemental de derecho romano. Buenos Aires: Editorial Araújo, 19-?

PONTES DE MIRANDA, Francisco Cavalcanti. Comentários ao Código de Processo Civil. Rio de Janeiro: Forense, 1973.

PONTES DE MIRANDA, Francisco Cavalcanti. Tratado de direito privado. São Paulo: Borsoi, 1954.t. 2.

PONTES DE MIRANDA, Francisco Cavalcanti. Tratado de direito privado. São Paulo: Borsoi, 1954.t. 4.

POTHIER, Robert Joseph. Tratado das obrigações pessoais e reciprocas. Rio de Janeiro: H. Garnier Editor, 1906.t. 1.

RADBRUCH, Gustav. Filosofia do direito. Coimbra: Arménio Amado Editor, 1997.

RÁO, Vicente. Ato jurídico. São Paulo: Saraiva, 1981.

RODRIGUES JÚNIOR, Otávio Luiz. A influência do BGB e da doutrina alemã no Direito Civil brasileiro do século XX. O Direito, Lisboa, v. 1, p. 45-110, 2015.

ROPPO, Enzo. O contrato. Coimbra: Almedina, 2009.

RUGGIERO, Roberto de. Instituições de direito civil. São Paulo: Saraiva, 1971.v. 1.

SALDANHA, Nelson. Sobre a teoria geral do direito civil. In: BRANDÃO, Cláudio et al. (Coord.). História do direito e do pensamento jurídico em perspectiva. São Paulo: Atlas, 2012.

SARAMAGO, José. A jangada de pedra. São Paulo: Companhia das Letras, 2017.

SCHIOPPA, Antonio Padoa. História do direito na Europa: da Idade Média à Idade Contemporânea. São Paulo: WMF Martins Fontes, 2014.

SOUSA, Joaquim Ribeiro de. Cláusulas contratuais gerais e o paradigma do contrato. Coimbra: Almedina, 1990.

SOUZA NETO, José Soriano de. Da novação. São Paulo: Livraria Acadêmica Saraiva \& Cia, 1937.

TRABUCCHI, Alberto. Instituzioni di diritto civile. Padova: CEDAM, 1974. 
Vol.92 N.01 - Anno CXXIX

VILANOVA, Lourival. As estruturas lógicas e o sistema de direito positivo. São Paulo:

Noeses, 2010. 